\title{
Implicaciones bioéticas y en la salud humana a partir de la industria e ingeniería agro biotecnología-genética y su relación directa con la producción de alimentos, salud humana como DDHH Derechos Humanos y el principio precautorio
}

\author{
M.Sc. Elvis Alberto Cornejo Venegas \\ Administrador Centro Investigación Transferencia Tecnológica Educación para el Desarrollo CITTED UNED. La Perla \\ Fortuna San Carlos Alajuela; correo electrónico: ecornejo@uned.ac.cr
}

Recibido: 08 marzo 2016 Aceptado: 09 mayo 2016

"... a la fecha, no hay evidencias claras para afirmar que los alimentos transgénicos son seguros e inocuos para la salud." Jaime García.

"Es el respeto a la vida y, en primer lugar, a la dignidad de la persona humana, la norma fundamental inspiradora de un sano progreso económico, industrial y científico"

Presbítero Francisco Hernández, 1999.

\section{RESUMEN}

El siguiente trabajo se refiere a partir de un proceso reflexivo y critico descriptivo, sobre ¿Las implicaciones y Que impactos tienen las practicas agro biotecnológicas para la producción alimenticia y en la salud humana y sus riesgos a la luz de lo revelado por el principio precautorio y Bioéticas?

Palabras claves: Biotecnologías, alimentos, bioética, agroindustria, salud humana, Derechos Humanos.

\footnotetext{
ABSTRACT

The following paper deals from a descriptive and critical reflective process on do what impacts have implications and agro biotechnological practices for food production and human health risks in light of what is revealed by the precautionary principle and bioethics?
}

Key words: Technologies, food, bioethics, agribusiness, human health, Human Rights.

\section{Introducción}

La discusión bioética a partir de esta temática se ubica en el contexto de la agricultura industrial como modelo predominante en la economía mundial frente a la agricultura y sus miles años de etno conocimiento y practicas vinculadas con los recursos naturales y las culturas; ya que los alimentos tratados agro biotecnológicamente y los OGM (Organismos genéticamente modificados) transgénicos son una rama emergente y novedosa de un enfoque que sostiene que éstas prácticas son más científica, que representan per se el progreso y que es la única esperanza para cubrir las necesidades alimentarias de un mundo que sabemos padece de carencia de alimentos no por escasez en su producción mundial sino por una pésima distribución en función 
del mantenimiento de los precios y oferta más demanda a nivel internacional.

Ejemplo lamentable de esto lo representan la existencia de patentes sobre los cultivos alimentarios: soja, brazzeina y quinua entre otros según reportes del Patentamiento de la Vida bio piratería (2000).

Según autores como Herbert citado por García (2006) y en relación a esto nos indica:

"Por otra parte, los críticos de estos alimentos sostienen que el motivo subyacente de este modelo de producción está más relacionado con el control y la dependencia que desean ejercer las corporaciones sobre la agricultura que con producir alimentos para los seres humanos; además, su puesta en práctica conlleva inevitablemente riesgos e impactos ecológicos negativos que destruyen también la cultura y el conocimiento de la agricultura rural" García, 2006 y otros.

Por tanto 2 visiones y 2 modos de vida se contraponen la agricultura y forma de vida rural campesino indígena sostenible y orgánica en resistencia ante una agro industria de enclave extractiva monocultivos.

En medio de esto se encuentran las poblaciones dentro de los territorios y los impactos generados implican una colisión a elementos fundantes de la calidad de vida, dignidad humana, tradiciones alimentarias, las culturas diversas y los DDHH.

Derechos a una alimentación sana, a un medio ambiente sano, a las garantías de un Estado de Derecho que fomente la salud humana con prevención y tratamiento más el derecho a la información y acceso a un conocimiento integral sobre los alimentos.

\section{En definición directa con los transgénicos OGM y Principio precautorio}

Más allá de la excesiva aplicación de los agro tóxicos y agro fertilizantes como parte de las lógicas de un sistema corporativo de producción agro industrial intensiva y los impactos directos en la salud humana y en el medio ambiente, se revela otra forma de producción in novadora que implica cuestiones ecológicas, bio éticas, de los DDHH y de salud integral humana; por tanto una preocupación actual y un imperativo moral su discusión dialógica analítica y clara.

La modificación genética implica introducir en los alimentos, genes provenientes de otras especies (u organismos) y las controversias y diferendos sobre los alimentos genéticamente modificados gira en torno de ¿hasta qué punto son un riesgo y si vale la pena correrlo? Entre los riesgos y preocupaciones en esta área están los siguientes según Herbert, citado por García (2006): Alergias, resistencia a antibióticos, dolores musculares, alteración en contenidos nutricionales entre otros riesgos y consecuencias aún no revelados y probados contundentemente y de lo cual se desprende la aplicabilidad del Principio Precautorio como forma de expresar una preocupación integral sobre los efectos perniciosos devenidos de su consumo.

\section{Opinión de la Organización Mundial de la Salud (OMS) Cumbre Rio 1992 y Cartagena}

Importante fue que 23 de junio del 2005, la OMS, por medio del Departamento de Inocuidad Alimentaria, dio a conocer el informe Biotecnología moderna de los alimentos, salud y desarrollo humano: estudio basado en evidencias, el cual señala, con respecto a la realidad acerca de la seguridad para la salud y el ambiente de estos organismos, lo siguiente:

"La introducción de un transgén en un organismo receptor no es precisamente un proceso controlado, y puede tener varios resultados con respecto a la integración, la expresión y la estabilidad del transgén en el huésped"

"En el presente, no pueden generalizarse evidencias concluyentes sobre las ventajas ambientales ni sobre costos a partir del uso de cultivos GM. Las consecuencias pueden variar significativamente entre las diferentes características GM, los tipos de cultivo y las diferentes condiciones locales, incluyendo características ecológicas y agroecológicas" 
"En la actualidad, las diversas promesas de la biotecnología moderna que podrían tener un impacto sobre la seguridad alimentaria, todavía no se han realizado en la mayoría de los países en desarrollo"

“... los rasgos novedosos de los organismos genéticamente modificado (OGM) también pueden acarrear potenciales riesgos directos para la salud y el desarrollo humano. Muchos de los genes y rasgos usados en los OGM agrícolas, aunque no todos, son novedosos y no se conocen antecedentes de uso alimentario inocuo"

"Los OGM también pueden afectar la salud humana indirectamente mediante impactos perjudiciales sobre el medio ambiente o mediante impactos desfavorables sobre factores económicos (incluyendo el comercio), sociales y éticos"

En la Declaración de Río sobre el medio ambiente y el desarrollo en 1992 se estableció que: "con el fin de proteger el medio ambiente los Estados deberán aplicar ampliamente el criterio de precaución conforme a sus capacidades. Cuando haya peligro de daño grave o irreversible, la falta de certeza científica absoluta no deberá utilizarse como razón para postergar la adopción de medidas eficaces".

El Protocolo de Cartagena sobre Bioseguridad (2000) también integra el mismo principio e intenta generar un marco de políticas globales para que los Estados se hagan cargo de los OGM.

Conviene asimismo, preservar las técnicas tradicionales de cultivos, las variedades de semillas y fomentar el desarrollo de una agricultura sostenible, mediante tecnologías alternativas que reduzcan el impacto ambiental, que promuevan la autosuficiencia y el control local de los recursos económicos como medios para lograr una distribución más justa de los beneficios procurando así un bienestar colectivo con integración de DDHH.

Así pues, para que la biotecnología sea viable y pueda ofrecer todo su potencial deberá realizarse en el marco de los principios éticos, en un continuo proceso de controversias y debates acerca de los fines últimos de este nuevo poder tecnológico. Para ello, es posible introducir valores ético-políticos en el desarrollo de la tecno ciencia actual, mediante principios y regulaciones globales.

\section{La industria mundial detrás del asunto, Bioética y los DDHH}

Según información de Hernández y Macdonald (2005), como es de sobra conocido, hay cinco Transnacionales que se reparten el mercado de los transgénicos y nos brindan los siguientes datos sobre este reducido club del monopolio de los agro productos químicos, semillas y patentes.

Monsanto: con un $90 \%$ de la superficie total sembrada con OGM y con sumas de $\$ 1900$ millones por venta de semillas M. G. y \$ 1800 millones por venta del herbicida Roundup. Syngenta: con un 2\% de sus ventas que corresponde a OGM.Bayer: que a su vez asumió la empresa Aventis CropScience.

Du pont: que adquirió Pioneer Hi-Bred (1999). Dow agrosciences: que también adquirió varias empresas, incluida Mycogen.

Las megas corporaciones agroquímicas que controlan la dirección y los objetivos de la innovación agrícola a través de la biotecnología aducen que la ingeniería genética contribuirá a mejorar la sostenibilidad de la agricultura resolviendo los muchos problemas que afectan a las actividades tradicionales del campo y conseguirá extirpar el hambre y la pobreza del Tercer Mundo mejorando su producción.

A los partidarios de la biotecnología se les contempla como poseedores de un sentido utilitario de la naturaleza a la vez que favorecen el libre comercio y los beneficios económicos frente a los daños ecológicos y las subsiguientes consecuencias que puedan acarrear para la humanidad.

En el centro mismo de la crítica se encuentran los efectos que la biotecnología produce en las condiciones sociales y económicas y en los valores morales y religiosos. 
De aquí se desprenden posteriormente una serie de mitos sobre la ciencia aplicada a la industria de los alimentos, según Altieri (2006): La biotecnología beneficiará a los campesinos de Estados Unidos y del mundo desarrollado.

- La biotecnología beneficiará a los pequeños agricultores y acabará con el hambre en el Tercer Mundo.

- La biotecnología no atenta contra la soberanía del Tercer Mundo

- La biotecnología conducirá a la conservación de la biodiversidad

- La biotecnología aumentará el uso de la biología molecular en beneficio de todos los sectores de la sociedad

Aunque la biotecnología mantiene su promesa de una sustancial mejora de la agricultura, dada su orientación actual, lo que realmente ofrece es dañar el medio ambiente, industrializar la agricultura y propiciar una mayor intrusión de los intereses privados en el campo de la investigación pública.

Se hace urgente para la sociedad civil y en marco términos de los Derechos Humanos, tener un fácil creciente y real acceso y a una mayor participación en las decisiones de ámbito tecnológico para que el dominio de la investigación científica por parte de las grandes corporaciones multinacionales se vea sometido a control público.

Las organizaciones públicas, tanto de autoridades nacionales como internacionales, como la FAO entre otras, deben llevar a cabo una monitorización y fiscalización cuidadosa para vigilar que los conocimientos no protegidos (etno conocimientos y sabiduría popular campesino indígena) no caigan en manos de las multinacionales y continúen siendo de dominio público para beneficio de las sociedades rurales y el mundo y no como obtenciones logradas por patentes otorgadas en bio prospección o también llamado por sus críticos bio piratería.

Hay que continuar desarrollando los diversos regímenes y mecanismos regulatorios de carácter público para incidir en contra al deterioro medioambiental y a los riesgos sociales y sanitarios que la biotecnología produce y podría producir.

\section{Ciencias y bioética conocimientos y prácticas, la salud integral y mercado}

Siguiendo a Hernández y sobre las biotecnologías, estas se refieren a toda aplicación tecnológica que utilice sistemas biológicos y organismos vivos o sus derivados, para la creación o modificación de productos o procesos para usos específicos y precisamente una de las biotecnologías más utilizadas en años recientes son las que implican la manipulación genética.

La bioética es el estudio interdisciplinario de los problemas éticos que surgen en la aplicación de la ciencia y la técnica en los ámbitos de la salud, la procreación, la alimentación. La bioética supone la unión de esfuerzos de biólogos y especialistas en ética con el fin de revisar, analizar y en lo posible, prever situaciones que afectan la calidad de vida de las personas o las comunidades. En este sentido también se le reconoce como ética biomédica.

En síntesis "es una disciplina que se esfuerza por poner en dialogo las ciencias de la vida y de la salud con la ética, como ciencia de los sistemas morales humanistas".

La transgénica y la ingeniería genética conllevan importantes retos y difíciles conflictos a la comunidad científica y para los estudiosos de la ética y Derechos Humanos del Siglo XXI, representa toda una temática de pertinente debate ético moral filosófico médico sanitario ecológico y por tanto interdisciplinar e intersectorial.

Hasta que nosotros como sociedad o como una entidad globalizada podamos asumir y estar de acuerdo sobre si los entes humanos o no humanos merecen nuestro respeto y estatus moral y legal, podremos esperar un debate y discusión interdisciplinario intenso, a medida que la ciencia y la medicina continúen creando nueva vida inteligente.

En el caso que nos ocupa, no sólo son válidos los valores intrínsecamente pragmáticos, técnicos, epistémicos, económicos, productivos o agronómicos de la tecnología de los transgénicos. También deben entrar en acción valores 
éticos relativos a la seguridad, la prevención de daños probables, la distribución equitativa de los costos, riesgos, la protección de la biodiversidad, la igualdad de condiciones en la producción y el comercio, la validación social y democrática de las innovaciones tecnológicas; por tanto abogar por una sociedad inclusiva $\mathrm{y}$ democracia cultural.

El sistema de valores que están relacionados con los transgénicos de primera generación (el maíz Bt, el algodón Bt, la soya y el algodón RR [Roundup Ready]) incluye finalidades como: mayor rentabilidad para los productores (retraso de maduración, reducción de pérdidas, fortalecimiento de las plantas), aumentos en la productividad agrícola, mayor resistencia a enfermedades y pestes reduciendo el uso de agroquímicos, mayor resistencia a sequías o inundaciones. Los beneficios de la segunda generación de OGM comprenderían: incrementos en la calidad y poder nutricional de los alimentos (el arroz dorado para ayudar a prevenir deficiencias en vitamina A y hierro). Y los de tercera generación: eliminación de elementos considerados como nocivos a la salud, disminución de efectos alergénicos, incorporación de vacunas y aditamentos nutritivos (como los antioxidantes) o medicinales, producción de biocombustibles (etanol) y plásticos biodegradables, en la ética aplicada, la bioética, eco etica y la ética de la tecno ciencia. Esos cuatros principios forman un sistema en interacción y comprenderían subsistemas de valores que guían las prácticas tecno científicas. Los principios son: responsabilidad, precaución, justicia y protección de la autonomía. Ninguno de los cuatro se impone de manera absoluta.

Una acción tecnológica éticamente aceptable debe poder satisfacer en una mínima medida los cuatros principios.

Ahora los siguientes puntos a modo de conclusión y en dialogo con Hernández (2005):

1. La ética como búsqueda de una actitud o conducta correcta enfrenta hoy día el problema de un modelo de desarrollo globalizado que se caracteriza por un carácter excluyente y asimétrico para las mayorías. En esta orientación "cuando en el mundo globalizado se imponen leyes políticas, jurídicas y económicas que llevan a la exclusión creciente de seres humanos, esta es una señal de que la ley no sirve su propósito principal, el propósito de servir a la vida humana de proteger a la persona vulnerable, como un ser frágil y digno (entonces) surge el carácter inmoral del neoliberalismo... que da prioridad absoluta a la propiedad y al contrato aún al costo de tantas vidas humanas"

2. Bajo este marco o modelo de desarrollo y con esa lógica privatizadora y de acumulación que acompañan los actuales procesos biotecnológicos, "por precaución y respeto a la vida humana, se impone poner en cuarentena a los transgénicos y se informe comunicativamente sobre ellos.

3. En atención a los principios éticos es bueno y necesario que se plantee en la sociedad un debate serio y riguroso, donde todos los actores o intereses, en iguales condiciones de participación e incidencia, puedan ayudar a identificar las dimensiones riesgos o consecuencias que conlleva la aplicación o uso de los OGM.

4. Es urgente para los diversos sectores de la sociedad civil desarrollar una mayor participación en las decisiones tecnológicas que se aplican y les afecta. Se requiere del monitoreo y el control de los conocimientos que éticamente no pueden seguir siendo propiedad de minorías del capital, dado que son producidos por la colectividad y para beneficio de todas las poblaciones.

5. Como señala la agencia británica Chistian Aid: "Nunca en la historia de la humanidad un comparativamente reducido número de corporaciones privadas ha manejado tanto poder... el poder de las corporaciones transnacionales necesita ser traído bajo control democrático".

6. Consecuente con los puntos anteriores, es tarea nuestra, en nuestro país, reforzar las acciones que garanticen ese control democrático por la vida, salud y el ambiente. 


\section{Conclusiones}

Con la manipulación de las bases genéticas de la vida; sea vegetal, animal, humano o de microorganismos, la humanidad avanza, dentro del progreso establecido por la ciencia y el modelo de desarrollo hegemónico tecnológico. Pero a la vez, por este modelo impuesto, con ello nos enfrentamos de lleno a una lógica de industrialización y explotación de recursos naturales en función del corporativismo de la industria alimenticio farmacéutica agro química y en detrimento de los recursos tanto naturales como culturales.

La ética, entendida aquí principalmente como la búsqueda del comportamiento o actitud correcta, respecto a la vida de toda y todas las personas; no es considerada por la lógica que aplican las corporaciones y menos la consideración e implementación de la eco ética ni de la bioética cuando deben ser imperativos categóricos.

Es la vida misma la que está en juego con la manipulación alimenticia, tal como se aplica en el modelo de desarrollo actual y en donde se está devastando la cimiente misma de la vida: las semillas, las aguas, los suelos, y con ello la contaminación erosión genética y por ende consecuencia directa afectaciones a los diversos agro etno ecosistemas, sistemas culturales etnoconocimientos ancestrales y a la salud humana por tanto una violación estructurada y sistémica hacia los DDHH de las poblaciones y de sus territorios.

Con la introducción a gran escala de las técnicas de intervención genética, se inicia una nueva era biotecno científica, con un potencial de efectos positivos pero también negativos, que sobrepasan los límites espacio temporales hasta ahora conocidos.

Esto genera esperanzas de obtener nuevo instrumental técnico para mejorar la adaptación humana, y de los seres vivos en general, al ya afectado medio ambiente, pero, a la vez, potencia los temores de provocar daños, impactos, afectaciones y riesgos de incalculable dimensión y que, por su irreversibilidad, tendrían efectos nefastos a futuras generaciones; máxime cuando estamos refiriendo a los DDHH, la alimentación, nutrición y medio ambiente sano y la bio diversidad cultural frente a los excesos de los agroquímicos devenidos desde la revolución verde, la agroindustria y los transgénicos. De ahí la justificante de aplicar el Principio precautorio ante lo desconocido.

Esta notable expansión de la razón instrumental debe acompañarse de una fortificación a nivel social de la ponderación-valoración, lo cual asigna a la bioética la tarea de enriquecer y robustecer el discurso comunicativo e impactar en los modos de producción predominantes en nombre de una humanización de los procesos mundiales contemporáneos.

Esta tarea tiene un componente reflexivo fundamental, pero que sólo será eficaz si logra generar mecanismos de recomendación y de resolución que ayuden a regular y fiscalizar las actividades biotecno científicas en respeto del bien común integra por tanto de un Buen Vivir.

\section{Bibliografía}

Acción Internacional por los Recursos Genéticos. (2000). De patentes y piratas.

Altieri, M. (2006). Los mitos de la biotecnología aplicada a la agricultura: algunas cuestiones éticas.

Donelan, P. (2009). Cultivo de semillas. Ecology Action.

García, J. (2006). Alimentos transgénicos: Insertidumbres $y$ riesgos basados en evidencias.

Hernández, J. (2005). Ética y transgénicos.

Linares, J. (2009). Una perspectiva ética sobre los transgénicos.

MacDonald, L. (2005). Cuestiones Éticas de la Ingeniería Genética y la Transgénica.

\section{Sitios de internet consultados}

http://www.usergioarboleda.edu.co/derecho/Biotec.html

http://www.scielo.cl/scielo.php?script=sci_ arttext\&pid=S1726-569X2001000200007

http://www.monografias.com/trabajos63/alimentos-transgenicos/alimentos-transgenicos 2. shtml\#xbioet

http://www.actionbioscience.org/esp/biotecnologia/glenn. html\#fullbio

http://www.findarticles.com/p/articles/mi_m0RUD/is_71/ ai_n16879626 